\title{
A RELEVÂNCIA DA COMUNICAÇÃO RURAL NA DIFUSÃO DE INFORMAÇÕES PARA A AGRICULTURA FAMILIAR: UM ESTUDO DE CASO DO "CODAF"
}

\author{
Silvia Cristina Vieira ${ }^{1}$ \\ Cristiane Hengler Corrêa Bernardo ${ }^{2}$ \\ Ricardo César Gonçalves Sant'Ana ${ }^{3}$
}

\section{RESUMO}

No atual cenário de desenvolvimento tecnológico, a relevância da comunicação rural na difusão de informações para a agricultura familiar aponta crescente vínculo com a obtenção de acesso às competências digitais. Este desafio harmonizaações nas áreas vinculadas ao processo comunicacional e ao uso das ciências da informação. Com abordagem metodológica qualitativa, por meio de um estudo de casodo Projeto de Extensão CoDAF, buscou-se compreensão dos fatos já mencionados, e na intençãode preencher uma lacuna bibliográfica que vincule a comunicação com a extensão universitária surge a questão - como o processo de comunicação interfere nos projetos de extensão universitária visando atingir público-alvo específico?Como objetivo principal pontua-se a analisedos fatores relacionados ao processo comunicacional de projeto de extensão que atua no contexto do acesso à informação para o meio rural. Conclui-se que a comunicação eficiente e específica é um elemento fundamental e norteador para atingir objetivos nos projetos de extensão universitários, sobretudo, aqueles que se destinam ao público rural.

PALAVRAS-CHAVE: Extensão. Agricultura familiar. Comunicação rural.

\section{THE RELEVANCE OF THE RURAL COMMUNICATION IN THE DISSEMINATION OF INFORMATION FOR FAMILY AGRICULTURE: A CASE STUDY "CODAF"}

\begin{abstract}
1 Mestranda em agronegócio e desenvolvimento, especialista em gestão do agronegócio e HIPOA/Vigilância sanitária de alimentos, graduada em medicina veterinária. Membro do Projeto de Extensão CoDAF e dos Grupos de Pesquisa CEPEAGRO e PGEA. UNESP. Email.tinavieiragomes@hotmail.com.br

${ }^{2}$ Doutora em educação, mestre em comunicação midiática e graduada em jornalismo. Professora assistente doutora. UNESP. Membro dos Grupos de Pesquisa CEPEAGRO e PGEA. Email.cristiane@tupa.unesp.br

${ }^{3}$ Doutor em Ciência da Informação. Curso de Administração - UNESP - Campus de Tupã; Programa de Pós-Graduação em Ciência da Informação - UNESP - Campus de Marília. ricardosantana@marilia.unesp.br
\end{abstract}


In the present scenario of technological development, the relevance of rural communication in the dissemination of information for family farms growing bond points with getting access to digital skills. This challenge harmonize actions in the areas linked to the communication process and the use of information sciences. With qualitative approach, through a case study of CoDAF extension project, we sought to understand the facts already mentioned, and the intention to fill a bibliographic gap that link the communication with the university extension the question arises - how the process Communication interfere in university extension projects to reach specific target audience? The main objective scores to analyze the factors related to the communication process of extension project which operates in the context of access to information for rural areas. It is concluded that the efficient and specific communication is a key element and guiding to achieve objectives in university extension projects, particularly those intended for the rural public.

KEYWORDS: Extension. Family farming.Rural communication.

\section{LA IMPORTANCIA DE LA COMUNICACIÓN RURAL EN LA DIFUSIÓN DE INFORMACIÓN PARA LA AGRICULTURA FAMILIAR: UN ESTUDIO DE CASO "CODAF"}

\section{RESUMEN}

Enelescenarioactualdeldesarrollo tecnológico, larelevancia de lacomunicación rural enladifusión de información para la agricultura familiar encrecimientopuntos de unión con laobtención de acceso a lascompetenciasdigitales. Este desafío de armonizarlasaccionesenlosámbitos relacionados con elproceso de comunicación y el uso de lasciencias de lainformación. Con enfoque cualitativo, a través de unestudio de caso delproyecto de extensiónCoDAF, hemos tratado de entender loshechosya mencionados, y laintención de llenarunvacío bibliográfico que enlazanlacomunicación con laextensiónuniversitaria surge la pregunta - cómoelprocesoComunicacióninterfiereenproyectos de extensiónuniversitaria para llegar al público objetivo específico? Los principales resultados objetivos para analizarlosfactores relacionados con elproceso de comunicacióndelproyecto de ampliación, que opera enel contexto delacceso a lainformación para las zonas rurales. Se concluye que lacomunicación eficaz y específico es un elemento clave y orientar para lograr los objetivos de losproyectos de extensiónuniversitaria, en particular las destinadas al publico rural.

PALABRAS CLAVE: Extensión. Agricultura familiar.Comunicación rural.

\section{INTRODUÇÃO}

O atual momento de desenvolvimento tecnológico aponta para a necessidade de se obter cada vez mais informações atualizadas, bem como possuir acesso às competências digitais. Tal necessidade induz o produtor rural a buscar novas alternativas na tentativa de suprir suas demandas e buscar atualização com relação às práticas, tecnologias, políticas públicas, fomentos, entre tantas outras temáticas, cujas informações nem sempre estão disponíveis para o produtor rural, sobretudo, aquele voltado para a agricultura familiar. 
A crescente importância que o acesso a dados vem obtendo em todas as áreas apresenta-se como novo desafio para áreas diretamente ligadas ao processo de comunicação e uso de tecnologias da informação (SANT'ANA, 2013).

Neste cenário, surge,no Campus da UNESP em Tupã, o Projeto de Extensão "Competências Digitais para Agricultura Familiar" (CoDAF), cujo objetivo é o decontribuir para que o acessoaoconhecimento, voltado para a agricultura familiar, esteja disponível e de fácil entendimento, ao alcance dos produtores rurais.

Para David et al. (2014) a extensão universitária se apresenta como uma via para estabelecer contato com a sociedade, procurando conhecê-la, entendê-la e estabelecer um diálogo permanente entre estas, para que assim,se possa encontrar soluções às demandas sociais da população.

O CoDAF possui, como público-alvo prioritário, o grupo social constituído de integrantes da agricultura familiar. É importante pontuar-se que o agricultor familiar faz parte de um grupo que, em muitas regiões ainda, precisa do incentivo de projetos como este para que possam se manter em atividade produtiva com 0 máximo de informações e de acesso aos fomentos proporcionados pelas políticas públicas que vem sendo implementadas em todas as esferas. Em algumas regiões do país, os sinais de vulnerabilidade econômica, social e cultural junto a estes produtores, são evidentes.

Reforça a condição do agricultor familiar junto ao modelo desenvolvimentista, Rocha (2006), ao dizer que indivíduos que estão à margem dos fluxos de conhecimento, poder e riqueza, tendem a estar excluídos de acesso a conteúdos informacionais, portanto, também às novas tecnologias. Nesse sentido, a extensão universitária ganha exponencial importância ao representar um caminho para contribuir com a sociedade, promovendo a inclusão dos agricultores familiares,por meio da interconexão desses grupos em rede,orientados por um processo comunicacional específico - a comunicação rural.

Segundo Borbenave (1983), para entender a comunicação no meio rural, torna-se necessário identificar as formas de agir e de pensar do homem rural, que por muitas vezes acabam gerando códigos e meios de comunicação próprios e particulares, construindo modelos específicos de comunicação. 
Complementam Sant'Ana e Bonini Neto (2014) que a coleta e tratamento de dados sobre a atividade agrícola, apesar de sua importância, encontra-se ainda distante de atingir todo seu potencial.

Para compreensão dos fatos já mencionados, e em busca de preencher uma lacuna bibliográfica que vincule a comunicação com a extensão universitária,surge a questão - como o processo de comunicação interfere nos projetos de extensão universitária visando atingir público-alvo específico?

Para tanto, propõe-se um breve resgate histórico do movimento de extensão universitária no Brasil, correlacionando este contexto aos instrumentos de comunicação usados pelo CoDAF, para promover o acesso dos agricultores familiares à informação.

\subsection{Extensão Universitária}

Para Souza (2001), o histórico da extensão universitária data do inicio da universidade europeia, tendo origem no mosteiro de Alcobaça em Portugal, por volta do ano de 1269. No caso brasileiro,são perceptíveis seus traços desde o Brasil Colônia, quando jovens universitários encontravam-se envolvidos com movimentos sociopolíticos da época. Embora, a extensão não fosse identificada com essa denominação, a forma de ação dos acadêmicos leva a defini-los como extensionistas, pois transferiam conhecimentos a comunidade.

O movimento de extensão universitário brasileiro fortaleceu-se numa variante do conceito da extensão rural, ambos provenientes do modelo de extensão norte americano (ROCHA, 2003).

Ao analisar definições de extensão universitária, Rocha (2006) relata que se deparou com um universo demasiadamente amplo, por vezes ambíguo. Aponta que a definição pode partir de um critério negativo,no qual aquilo que não se enquadra como ensino ou pesquisa é classificado como extensão. Segundo o autor, esse critério acaba reduzindo a extensão universitária a uma verdadeira "vala comum" que comporta toda e qualquer atividade produzida pelas universidades, o que muitas vezes é contraditória com seus objetivos, missão institucional e cultura acadêmica. 
A extensão universitária no país foi oficializada por meio do Decreto Lei 252 de 1967, em cujo artigo número 10 estabelece-se que "a universidade pública em sua missão educativa deverá estender à comunidade, sob a forma de cursos e serviços, as atividades de ensino e pesquisa que lhe são inerentes".

Silveira (1987) aponta que, por meio da reforma universitária de 1968,passam a constituir a área de atuação básica da universidade pública - o ensino, a extensão e a pesquisa. Com a criação do Ministério da Educação e Cultura $\left(M^{4} C^{4}\right)$, em 1971, foi estabelecida a Coordenação Nacional de Extensão, promovendo a divulgação e implantação da extensão em universidades públicas no Brasil.

Uma extensão universitária consiste na definição e execução de projetos e programas com ativo envolvimento das comunidades, para o enfrentamento de problemas, cuja solução favorece tanto os cidadãos demandantes, como contribuem positivamente para oresultado de pesquisas científicas e nos resultados do próprio projeto de extensão, que também faz parte da formação de um profissional cidadão.

$\mathrm{O}$ ato de compreender a extensão como função de estender o que antes estava circunscrito à Universidade, levar informações à comunidade, principalmente por meio de projetos de extensão universitários como o CoDAF, confirmam a importância da extensão dentro da academia, formando verdadeiras redes de transferência de conhecimento.

Salienta Rocha (2006) que o efeito deste processo de formação de redes, constituído pela extensão universitária e, articulado globalmente,temrepercussão e ação diretasentidas localmente. Nesta direçãoé que o CoDAF propicia, a todos os internautas, acesso ao conteúdo informacional disponível no site. Além do ambiente virtual, tem também os cursos e capacitações presenciais, realizados no entorno da sede do projeto, no município de Tupã, estado de São Paulo.

O portalCoDAF hospedado no endereço http://codaf.tupa.unesp.br/no item "sobre o CoDAF", descreve que o "Projeto Competências Digitais para Agricultura Familiar é um projeto de extensão da Universidade Estadual Paulista "Júlio de Mesquita Filho", campus de Tupã,que tem como objetivo proporcionar alternativas para amenizar os fatores que dificultam o acesso à informação por parte de

\footnotetext{
${ }^{4}$ Atualmente a sigla MEC refere-se apenas ao Ministério da Educação, pois houve o desmembramento e a cultura foi para um novo ministério.
} 
agricultores familiares, como a baixa familiaridade com as tecnologias digitais e escassos sistemas de informação específicos para este público".

Neste sentido, o Projeto CoDAF atua no desenvolvimento de cursos e oficinas preparatórias, visando desenvolver competências técnicas e informacionais, ampliando as possibilidades de competitividade destes agricultores, no que tange ao acesso às informações sobre o setor e o mercado, e na divulgação de suas práticas, culturas e diferenciais competitivos.

Para tanto, por meio de um elemento concentradorno portal CoDAF são divulgados cursos e atividades desenvolvidas pelo Projeto, além da disseminação de informações e conteúdos importantes para agricultores familiares, como informações sobre programas governamentais de apoio, vantagens da agricultura familiar e suas principais características.

E, para desempenhar a missão de transmitir o conhecimento e tecnologias de informação para quem necessita, neste período de revolução tecnológica, tornase fundamental ao projeto CoDAF, amparos em Sant'Ana (2013, p.2), o reconhecimento e a contribuição em todas as fases e fatores do processo de acesso a dados, o que leva à necessidade da elaboração de um modelo que sirva de base para compreensão sobre: "quais são estas fases; como elas se relacionam; quais os fatores envolvidos em cada uma delas; quais os recursos disponíveis; como tirar o melhor proveito de cada uma delas, e; como é possível melhorá-las".

No sentido de ampliar esse potencial, o portal CoDAFtambém permite que sejam apresentadas informações sobre os produtores, como dados de sua propriedade e características de seus produtos, disponibilizando no website uma área especialmente para esta finalidade. Desta forma, além de ofertar produtos, os agricultores poderão dar publicidade às boas práticas e às ações de responsabilidade socioambiental desenvolvidas em suas propriedades.

O público-alvo do Projeto são os membros da agricultura familiar, mas o site também contempla informações úteis aos demais interessados nesta área específica do agronegócio, com apresentação de artigos científicosque relatam as conquistas do projeto, agenda de eventos, trabalhos técnicos e acadêmicos, entre outras informações. 
O portal CoDAF mantém canal direto de comunicação com os internautas por meio do "fale conosco", o que favorece o fluxo bilateral de informações entre pesquisadores, extensionistas e produtores da agricultura familiar, favorecendo a relação dialógica no meio rural.

É nessa lógica que o setor rural está sujeito a modelos de desenvolvimento rural que "determinam certas maneiras de utilizar a comunicação que nem sempre coincidem com os modos urbanos de fazê-lo" (BORDENAVE, 1983, p.11).

Essas especificidades, de acordo com Bordenave (1983), relacionam-se, principalmente, a fatores como complexidade dos agronegócios e ao o modo de pensar e agir do produtor rural. Bernardo e Bernardo (2013) complementam esse argumento com outros fatores, tais como: divulgação correta do conceito de agronegócio e, neste se insere o sentimento de não pertencimento do agricultor familiar ao setor; a heterogeneidade dos públicos; relações conflituosas entre agronegócio e meio ambiente e por fim aos aspectos geográficos que muitas vezes representam limitadores importantes para o acesso às tecnologias.

É nesse contexto que se insere o perfil do agricultor familiar que vai além de toda a complexidade da produção rural, apresentando problemas bastante localizados e que, muitas vezes, poderia ser resolvido pela simples igualdade de acessibilidade à informação. Para entender melhor essa conformação, torna-se importante uma breve reconstrução do cenário mais recente em que se desenvolve a agricultura familiar no Brasil.

\subsection{O perfil da agricultura familiar}

O Brasil é um país de extensão territorial continental e apresenta características peculiares distintas na agricultura familiar ao longo das variadas regiões. No entanto, tal heterogeneidade não impediu que,em 24 de junho de 2006, se estabelecessena legislação parâmetros lineares de enquadramento para 0 agricultor familiar.

A Lei 11.326/2006 estabeleceu as diretrizes oficiais para a formulação da Política Nacional da Agricultura Familiar e Empreendimentos Familiares Rurais 
(BRASIL, 2006).Adotou-se para delimitar o público, o uso "operacional" do conceito, centrado na caracterização geral de um grupo social bastante heterogêneo. Já no meio acadêmico, encontram-se diversas reflexões sobre o conceito de agricultura familiar, propondo um tratamento mais analítico e menos operacional do termo.

Em fase de conceituação, Altafin (2007)relata que, ao se buscar na literatura contribuições para a delimitação conceitual da agricultura familiar, encontram-se diversas vertentes, dentre as quais se destacam duas. Uma delas considera que a moderna agricultura familiar é uma nova categoria, gerada no bojo das transformações experimentadas pelas sociedades capitalistas desenvolvidas. E a outra defende ser a agricultura familiar brasileira um conceito em evolução, com significativas raízes históricas.

A necessidade dos agricultores aumentarem seu próprio conhecimento revela-se com a evolução na história da humanidade, indo de uma fase extrativista, com apropriação de recursos disponíveis, obtidos facilmente na natureza, para um ambiente onde se torna indispensável obter informações e capacitações para manter produtividade, plantando e colhendo com a utilização das tecnologias de manejo disponíveis (DUARTE, 2004).

Cada vez mais, a informação torna-se ferramental útil para o desenvolvimento do agronegócio nacional com ênfase ao segmento da agricultura familiar que encontra barreiras físicas, geográficas, digitais e comunicacionais, para decodificar as informações disponíveis por meio do processo dialógico.

\subsection{Processo de comunicação}

Definir regras para a comunicação caracteriza cada experiência pessoal e cada sociedade. A comunicação é ao mesmo tempo realidade e modelo cultural. "Do ponto de vista intuitivo, comunicar consiste em compartilhar com o outro. Simplesmente não há vida individual e coletiva sem comunicação, não há seres humanos sem sociedade como não há sociedade sem comunicação" (WOLTON, 2004, p. 30). 
Bahia, (1995) aponta que, para que ocorra uma comunicação eficaz, os sistemas ou estruturas de comunicação necessitam demonstrar consistência profissional, adequada apresentação, compatibilidade de pensamentos e ação, e bidirecionamento. Este processo deve ser genuinamente benéfico para todos os envolvidos no processo de comunicação.

Barreiras de compreensão podem ser eliminadas a partir de diversas práticas e, com segurança, a instituição de canais de comunicação é uma delas. Deste modo, no interesse da transferência de informação e visando integração social, o espaço reservado à empresa, neste caso à empresa rural e, ao produtor, deve ser ocupado sem preconceito ou limite, fomentando o acesso a dados atuais e úteis, divulgados de maneira ampla e democrática.

Para tanto, conforme salientam Sant'Ana e Bonini Neto, (2014) nota-se a importante contribuição da ciência da informação, neste procedimento de transferência de conhecimentos por meio eletrônico. Com estudo e identificação dos processos e fatores envolvidos no ciclo de vida dos dados, pode-se contribuir com este processo de democratização do uso dos dados, estruturando tanto as informações sobre o tema, como contribuindo para divulgação destas e em âmbito mais amplo, viabilizando a mediação no acesso a estes conhecimentos, contribuindo no processo de repasse de informação.

É importante salientar que as informações passam a ser elaboradas a partir dos dados, na medida em que estes são selecionados e organizados de modo a produzir elementos suficientes para serem transformados em informação.

A informação é requisito básico para a tomada de decisões no campo, cenário onde o produtor rural deve decidir com antecedência seu planejamento de produção. Por isso, as informações apresentadas ao agricultor, devem ser eficientes e disponibilizadas de maneira adequada (DUARTE, 2004).

No caso da comunicação no meio rural, são necessárias habilidades e atitudes peculiares para estabelecer diálogo consistente, no qual emissor e receptor devem estar alinhados com vocabulário, afinidades e valores, buscando a confiabilidade mútua como arcabouço necessário para se estabelecer fluxo bilateral de informações. 
Neste sentido, utilizar um processo de comunicação adequado ao públicoalvo específico é um processo que pode subsidiar o entendimento da mensagem, no caso do produtor rural, essa distinção já foi identificada.

Quando se trata de diferenciação da comunicação rural para a comunicação urbana, Bordenave (1993) aponta uma justificativa que ampara esta distinção, destacando o fato da população rural concentrar seu modo de vida e seu comportamento ao redor de uma atividade específica e diferenciada da urbana.

A comunidade rural possui especificidades nos modos, costumes, vestuário e vocabulário próprio, o que reflete diretamente na gestão do processo de comunicação e na decodificação das informações que não utilizam linguagem adequada, causando comunicação ineficiente.

Complementam Bernardo e Bernardo (2013, p. 44) que se nota a heterogeneidade dos públicos que são abrangidos pelo agronegócio e que obrigam uma comunicação mais segmentada e, por consequência, o uso de diferentes códigos e meios. O indivíduo rural não é mais apenas o chamado "matuto" de tempos passados. "Já faz algum tempo que esse cenário vem sendo alterado e tem trazido para a comunicação uma heterogeneidade de públicos, com culturas diversas e níveis de formação muito variados".

O problema identificado como comunicação ineficiente, não se refere à inexistência de informações, mas ao conhecimento sobre sua disponibilidade e acesso ao conteúdo, entendimento, avaliação sobre seu potencial, além da adaptabilidade e capacidade de utilizá-la de maneira adequada, personalizada a sua realidade (DUARTE, 2004).

Neste sentido, o CoDAF, oportuniza a inclusão digital e o repasse de informações e novas tecnologias para público específico do agronegócio. E nesse processo, a escolha do processo comunicacional adequado, minimizando ruídos, favorece a eficiência dialógica.

\section{OBJETIVOS}

Analisar os fatores relacionados ao processo comunicacional de projetos de extensão que atuam no contexto do acesso à informação para o meio rural, destaca- 
se como principal objetivo. E, como objetivos específicos, têm-se: caracterizaro principal público-alvo do CoDAF; identificar as ações de comunicação do projeto; verificar a adequação das informações disponíveis para o produtor rural.

\section{METODOLOGIA}

De caráter exploratório, por meio de um Estudo de Caso, tendo como objeto de análise o CoDaf, a pesquisa buscaentender, esclarecer e remodelar conceitos e ideias visando à formulação de problemas mais precisos, envolvendo levantamento bibliográfico, documental e vivencia empírica na participação do Projeto de Extensão universitária "CoDAF" .

A escolha do método de pesquisa justifica-se devido às lacunas existentes nos estudos científicos sobre a transferência de informações e tecnologiaspara o produtor rural, sobretudo, por meio dos projetos de extensão universitária. Principalmente, voltados para público-alvo como o agricultor familiar, que demanda um processo de comunicação diferenciado do utilizado para o público urbano (BORDENAVE, 1983).

O artigo foi formatado sob oviés metodológicode uma abordagem qualitativa, que por sua vez busca analisar e interpretar aspectos profundos, descrever a complexidade do comportamento humano, com riquezas de detalhes das investigações, hábitos, ações, tendências comportamentais, entre outros (MARCONI; LAKATOS, 2011).

O estudo de caso único, adotado na pesquisa, faz-se necessário, por ser uma análise de um Projeto de Extensão universitário inédito, voltado um público-alvo que carece de receber informações específicas e desenvolver suas competências digitais, com inclusão em um universo cibernético ainda hoje, pouco usual a esta classe de agricultores.

De acordo com Yin (2005), o estudo de caso como estratégia na pesquisa, justifica-se, pois focaliza o âmbito das decisões, tenta esclarecer os motivos pelo qual as decisões foram tomadas, como foram implantadas e quais os resultados 
estabelecidos. Trata-se de um caso empírico, que investiga um fenômeno atual, dentro de um contexto de realidade.

\section{RESULTADOS}

Para que o compromisso social da universidade ocorra do ponto de vista da extensão, é preciso investir dentro dos programas de projetos de extensão que, de alguma maneira, estimulem uma relação de proximidade entre a universidade e a sociedade, favorecendo que a comunidade passe a ser sujeito do processo e não apenas beneficiária do mesmo (ROCHA, 2004). Dessa maneira, o CoDAF atua buscandonecessidades dos agricultores familiares, visando atender às demandas reais da sociedade e envolvendo-a no processo de planejamento participativo das ações.

A dinâmica de triagem, recebimento e disponibilização de informações no portal e redes sociais são realizadas pelos integrantes do grupo permitindo um processo de interação interdisciplinar, coordenada e orientada para resultados participativos, visando o repasse de informações úteis no cenário rural produtivo brasileiro, com foco prioritário em novas tecnologias.

Em virtude dessas características, elaborou-se um quadro analítico com o objetivo de diagnosticar se o portal corresponde às especificidades da comunicação rural. Conforme se pode conferir no quadro a seguir:

Quadro 1 - Fatores que tornam a comunicação rural específica

\begin{tabular}{|c|l|}
\hline $\begin{array}{c}\text { Fatores segundo } \\
\text { Bordenave (1983) }\end{array}$ & \multicolumn{1}{|c|}{ Portal do CoDAF } \\
\hline $\begin{array}{c}\text { Complexidade do } \\
\text { Agronegócio }\end{array}$ & $\begin{array}{l}\text { Não aborda todos os grupos integrantes da cadeia, uma vez que o projeto tem } \\
\text { como foco a agricultura familiar. }\end{array}$ \\
\hline $\begin{array}{c}\text { Formas de agir e } \\
\text { pensar do homem } \\
\text { rural }\end{array}$ & $\begin{array}{l}\text { A linguagem mais simples e de fácil entendimento, assim como a utilização de } \\
\text { imagens, favorecem a navegação para usuários que não tenham tanta } \\
\text { habilidade digital. } \\
\text { Ao trazer o agricultor familiar para a uma maior proximidade com o projeto } \\
\text { CoDAF estimula-se o sentimento de confiança que faz com que este esteja } \\
\text { mais receptivo às informações, além de estimular o fluxo bilateral de } \\
\text { informações. }\end{array}$ \\
\hline $\begin{array}{c}\text { Modelo de } \\
\text { desenvolvimento } \\
\text { rural }\end{array}$ & $\begin{array}{l}\text { O portal auxilia no sentido de promover uma opção de informação ao produtor } \\
\text { rural que, diante de um modelo de desenvolvimento rural segregador, o coloca } \\
\text { em condição de isolamento e o torna muitas vezes incomunicável. O portal }\end{array}$ \\
\hline \hline
\end{tabular}




\begin{tabular}{|c|c|}
\hline & $\begin{array}{l}\text { ainda dá voz ao agricultor familiar, dando espaço a este para apresentação dos } \\
\text { seus produtos ao mercado, proporcionando melhores condições de } \\
\text { competitividade e ampliando os canais de comercialização que para este grupo } \\
\text { encontram-se muitas vezes limitados. }\end{array}$ \\
\hline \multicolumn{2}{|l|}{$\begin{array}{l}\text { Fatores segundo } \\
\text { Bernardo e } \\
\text { Bernardo (2013) }\end{array}$} \\
\hline $\begin{array}{l}\text { Disseminação } \\
\text { correta do conceito } \\
\text { de agronegócio }\end{array}$ & $\begin{array}{l}\text { Define detalhadamente o conceito de agricultura familiar que é o recorte } \\
\text { abordado pelo projeto. }\end{array}$ \\
\hline $\begin{array}{l}\text { Heterogeneidade } \\
\text { dos públicos }\end{array}$ & $\begin{array}{l}\text { Apesar do portal por ser direcionado, prioritariamente, a um público de } \\
\text { agricultores familiares também pode ser acessado por pesquisadores e público } \\
\text { de maneira geral que tenha interesse na temática. Neste caso utiliza uma } \\
\text { linguagem mais simples para que seja da compreensão de todos os públicos. }\end{array}$ \\
\hline $\begin{array}{l}\text { Relação } \\
\text { conflituosa entre } \\
\text { agronegócio e } \\
\text { meio ambiente }\end{array}$ & $\begin{array}{l}\text { O portal auxilia na ação de minimizar o conflito entre produção agropecuária e } \\
\text { meio ambiente por meio das divulgações de atividades produtivas sustentáveis } \\
\text { e das inovações que beneficiam a atividade com redução de impacto ao meio } \\
\text { ambiente. Ainda se pode afirmar que, o portal oferece orientações sobre } \\
\text { legislações, práticas, consciência ambiental, enfim, a ação promovida pelo } \\
\text { portal é educativa, ao passo que ao levar a informaçâo sobre as formas } \\
\text { corretas de produção sustentável e inovações também está exercendo o papel } \\
\text { educativo ao propiciar ao produtor rural uma inclusão digital. }\end{array}$ \\
\hline
\end{tabular}

Fonte: elaborado pelos autores

Nesse espaço dialógico, propiciado pelo CoDAF, criam-se vínculos e comprometimentos entre os sujeitos, que antes não existiam. Esse diálogo é fortalecido por meio de um processo de comunicação voltado, prioritariamente, ao produtor rural e que envolve algumas características próprias e especificidades que devem ser respeitadas para que se tenha maior eficiência comunicacional (BORDENAVE, 1983; BERNARDO e BERNARDO, 2013).

Os eventos realizados, por meio do projeto, foram direcionados para produção e desenvolvimento de tecnologias úteis para o campo, como o evento eCoDAF, realizado em 2014.

O curso "Uso de planilhas na gestão de propriedades rurais", realizado em 2015, proporcionou inclusão digital aos produtores da agricultura familiar, direcionado à gestão e ao controle de estoque da empresa rural, fomentando contribuição no campo da competitividade e do empreendedorismo no segmento específico do agronegócio, por meio do uso de planilhas eletrônicas desenvolvidas para as necessidades do grupo de produtores, atendendo uma demanda préestabelecida. 
Surge assim, uma real interação entre academia e comunidade, papel fundamental da extensão universitária, na qual a sociedade emergente desse processo de transformação tecnológica é capacitada e incluída no universo digital.

Dentre outras ações destacadas, como os cursos oferecidos, o portal CoDaf representa um canal de comunicação importante entre a universidade e os produtores rurais. É por meio dele que são estabelecidos os diálogos em que são coletadas as demandas dos produtores, assim como são enviadas as informações sobre as temáticas de interesse do agricultor familiar.

\section{CONCLUSÕES}

Conclui-seque a comunicação eficiente e específica é um elemento fundamental e norteador para atingir os objetivos nos projetos de extensão universitários, sobretudo, aqueles que se destinam ao público rural.No caso da agricultura familiar, o público rural demanda um processo comunicacional diferenciado do urbano.

Nesta linha, o Projeto de extensão CoDAF atua de maneira a agregar valores, estender dados úteis à comunidade e promover a inclusão digital para integrantes da agricultura familiar, respeitando as características do público-alvo.Ao introduzir conceitos, notícias e ministrar cursos, adota uma linguagem acessível, mesmo quando aplicam conteúdos técnicos, como os trabalhados no curso de planilhas para gestão.

O portal é bastante amigável, faz utilização de ícones que facilitam a identificação dos temas por meio de figuras,seguidos de descritivos por escrito. As imagens e vídeos contribuem para reforçar o processo de comunicação com o produtor rural.

Além de carência informacionalno cenário rural, ressalta-se a importância do projeto dedicar prioridade para a agricultura familiar, pois a classe participa intensamente do processo de valorização do desenvolvimento local, baseado em conhecimentos endógenos, com o aproveitamento racional dos recursos naturais disponíveis em unidades territoriais delimitadas pela identidade sociocultural. 
Nesse contexto, a agricultura familiar é reconhecida como importante ator social, responsável por parte significativa das dinâmicas rurais e de grande relevância na articulação rural-urbana, especialmente em municípios menores,com forte aptidão ao agronegócio, a exemplo de Tupã.

\section{Referências}

ALTAFIN, I. Reflexões sobre o conceito de agricultura familiar. Texto trabalhado durante $03^{\circ}$ Módulo do Curso Regional de Formação Político-sindical da região Nordeste/2007. Disponível em <http://mstemdados.org/sites/default/files/Reflex\%C3\%B5es\%20sobre\%200\%20conceito\%20de\%20a gricultura\%20familiar\%20-\%20lara\%20Altafin\%20-\%202007 0.pdf>. Acesso em abr. 2015.

BAHIA, J. Introdução à Comunicação Empresarial. Rio de Janeiro: Editora Mauad, 1995.

BATERMAN, T.; SNELL, S. Administração. Porto Alegre: AMGH Editora. 2. ed, 2013.

BERNARDO, C.H.C.; BERNARDO, R. Gestão da Comunicação para o Agronegócio. Revista Cambiassu. UFMA n. 12. p. 43 - 55. jan/jun. 2013.

BORDENAVE, J.D. O que é comunicação rural. 3.ed. São Paulo: Editora Brasiliense, 1983.

Além dos meios e mensagens. Petrópolis: Editora Vozes, 2002.

BRASIL, 2006. Lei 11.326/2006. Disponível em <http://www.planalto.gov.br/ccivil 03/ ato20042006/2006/lei/l11326.htm>. Acesso em mar. 2015.

CODAF. Projeto Competências Digitais para Agricultura Familiar. Disponível em <http://codaf.tupa.unesp.br/>. Acesso em mar. 2015.

DAVID, A. C. C. AYALA, M. P. ROCHA, A. K. L. CAMPOS, M. F. H. Diálogo de experiências sobre extensão universitária e tecnologia social. Revista Raízes e Rumos. Vol. 02 № 01,116 - 155, Rio de Janeiro, Jun., $2014 . \quad$ Disponível em <http://www.seer.unirio.br/index.php/raizeserumos/article/view/3955>. Acesso em mai. 2015.

GIL, A.C. Métodos e técnicas de pesquisa social. 6.ed. São Paulo: Atlas, 2014.

LAKATOS, E. M; MARCONI, M. A. Metodologia científica. 6 ed. São Paulo: Atlas, 2011.

ROCHA, Roberto Mauro Gurgel. Extensão Universitária: momento de aplicação do conhecimento e de intercâmbio de saberes na relação universidade sociedade? In: THIOLLENT et al (Org.). Extensão Universitária: conceitos, métodos e práticas. Rio de Janeiro: Universidade Federal do Rio de Janeiro / Sub-Reitoria de Desenvolvimento e Extensão, 2003.

ROCHA, J. C. A reinvenção solidária e participativa da universidade: um estudo sobre redes de extensão universitárias no Brasil. Tese de doutorado, Salvador: 2006. Disponível em <https://repositorio.ufba.br/ri/bitstream/ri/10189/1/Rocha,\%20Jose\%20Claudio.pdf> . Acesso em mar. 2015.

. A certificação profissional de agentes de cidadania e direitos humanos. Brasília: Câmara dos Deputados: Unicidadania, 2004. Disponível em <www.fundaj.gov.br>. Acesso em mar. 2015.

SANT'ANA, R. C. G. Ciclo de vida dos dados e o papel da ciência da informação. In: XIV Encontro Nacional de Pesquisa em Ciência da Informação, 2013, Florianópolis / SC. Anais do XIV 
Encontro Nacional de Pesquisa em Ciência da Informação, 2013. Disponível em $<$ http://enancib.sites.ufsc.br/index.php/enancib2013/XIVenancib/paper/viewFile/284/319 >Acesso em mai. 2015.

SANT'ANA, R.C.G.; BONINI NETO, A. Análise de dados sobre produção de leite: uma perspectiva da Ciência da Informação. Informação e Tecnologia. V.1,Num.1, jan/jun, 2014. Disponível em <http://www.ies.ufpb.br/ojs2/index.php/itec/article/view/19493/10863>. Acesso em mai. 2015.

SILVEIRA, N. D. R. Universidade brasileira: a intenção da extensão. São Paulo: Loyola, 1987.

SOUSA, A. L. L. Concepção de extensão universitária: ainda precisamos falar sobre isso.

IN FARIAS, Dóris. Construção conceitual da extensão universitária na América Latina, Brasília: UNB, 2001.

YIN, R. K. Estudo de caso: planejamento e métodos. 3. ed. Porto Alegre: Bookman, 2005. 212p.

WOLTON, D. Pensar a comunicação. Brasília: Editora Universidade de Brasília, 2004. 